University of Nebraska - Lincoln

DigitalCommons@University of Nebraska - Lincoln

USDA National Wildlife Research Center - Staff Publications
U.S. Department of Agriculture: Animal and Plant Health Inspection Service

2015

\title{
Molecular characterization of Salmonella enterica isolates associated with starling-livestock interactions
}

James C. Carlson

USDA/APHIS/WS National Wildlife Research Center, james.c.carlson@aphis.usda.gov

Doreene R. Hyatt

Colorado State University

Kevin Bentler

USDA/APHIS/WS National Wildlife Research Center

Anna M. Mangan

USDA/APHIS/WS National Wildlife Research Center

Michael Russell

Colorado State University - Fort Collins

See next page for additional authors

Follow this and additional works at: https://digitalcommons.unl.edu/icwdm_usdanwrc

Part of the Life Sciences Commons

Carlson, James C.; Hyatt, Doreene R.; Bentler, Kevin; Mangan, Anna M.; Russell, Michael; Piaggio, Antoinette J.; and Linz, George M., "Molecular characterization of Salmonella enterica isolates associated with starling-livestock interactions" (2015). USDA National Wildlife Research Center - Staff Publications. 1738.

https://digitalcommons.unl.edu/icwdm_usdanwrc/1738

This Article is brought to you for free and open access by the U.S. Department of Agriculture: Animal and Plant Health Inspection Service at DigitalCommons@University of Nebraska - Lincoln. It has been accepted for inclusion in USDA National Wildlife Research Center - Staff Publications by an authorized administrator of DigitalCommons@University of Nebraska - Lincoln. 


\section{Authors}

James C. Carlson, Doreene R. Hyatt, Kevin Bentler, Anna M. Mangan, Michael Russell, Antoinette J. Piaggio, and George M. Linz 


\title{
Molecular characterization of Salmonella enterica isolates associated with starling-livestock interactions
}

\author{
James C. Carlson ${ }^{\mathrm{a}, *}$, Doreene R. Hyatt ${ }^{\mathrm{b}}$, Kevin Bentler ${ }^{\mathrm{a}}$, Anna M. Mangan ${ }^{\mathrm{a}}$, \\ Michael Russell ${ }^{\mathrm{b}}$, Antoinette J. Piaggio ${ }^{\mathrm{a}}$, George M. Linz ${ }^{\mathrm{c}}$ \\ ${ }^{a}$ U.S. Department of Agriculture, Animal and Plant Health Inspection Service, Wildlife Services, National Wildlife Research Center, 4101 \\ LaPorte Avenue, Fort Collins, CO 80521, USA \\ ${ }^{\mathrm{b}}$ Colorado State University, Veterinary Diagnostic Laboratories, College of Veterinary Medicine and Biomedical Science, 1644 Campus \\ Delivery, Fort Collins, CO 80523-1644, USA \\ ${ }^{\mathrm{c}}$ U.S. Department of Agriculture, Animal and Plant Health Inspection Service, Wildlife Services, National Wildlife Research Center, 2110 \\ Miriam Circle, Suite B, Bismarck, ND 58501-2502, USA
}

\section{A R T I C L E I N F O}

Keywords:

Antimicrobial resistance

European starlings

Bacteria

Enterobacteriaceae

Salmonella enterica

\begin{abstract}
A B S T R A C T
Bird-livestock interactions have been implicated as potential sources for bacteria within concentrated animal feeding operations (CAFO). In this study we characterized Xbaldigested genomic DNA from Salmonella enterica using pulsed-field gel electrophoresis (PFGE). The PFGE analysis was conducted using $182 \mathrm{~S}$. enterica isolates collected from a single CAFO between 2009 and 2012. Samples collected in 2012 were subjected to antimicrobial susceptibility testing. The analysis was limited to $S$. enterica serotypes, with at least 10 isolates, known to occur in both European starlings (Sturnus vulgaris) and cattle (Bos taurus) within this CAFO. A total of five different serotypes were screened; S. Anatum, $S$. Kentucky, S. Meleagridis, S. Montevideo, S. Muenchen. These samples were recovered from five different sample types; starling gastrointestinal tracts (GI), starling external wash, cattle feces, cattle feed and cattle water troughs. Indistinguishable S. enterica PFGE profiles were recovered from isolates originating in all sample types. Antimicrobial resistance (AMR) was also associated with indistinguishable $S$. enterica isolates recovered from all samples types. These data suggests that AMR S. enterica is transmitted between cattle and starlings and that shared feed sources are likely contributing to infections within both species. Moreover we isolated indistinguishable PFGE profiles across all years of data collection, suggesting long-term environmental persistence may be mediated by starling visits to CAFO.
\end{abstract}

Published by Elsevier B.V.

\section{Introduction}

Salmonella enterica is recognized as one of the most common causes of foodborne illness worldwide (Zhao et al., 2006). Within the United States of America, S. enterica infections are responsible for 1.3 million human cases of foodborne salmonellosis, resulting in 15,600

\footnotetext{
* Corresponding author. Tel.: +1 970266 6127; fax: +1 9702666138. E-mail address: James.C.Carlson@aphis.usda.gov (J.C. Carlson).
}

hospitalizations and 550 deaths each year (Mead et al., 1999; Zhao et al., 2006). Globally, S. enterica infections are responsible for 93.8 million human cases of salmonellosis, resulting in 155,000 deaths annually and $85.6 \%$ of all cases were foodborne (Majowicz et al., 2010). Human infections with S. enterica are primarily associated with the consumption of animal derived food products (Mead et al., 1999; Pang et al., 1995; Zhao et al., 2006).

S. enterica contributes to morbidity and mortality in livestock (Fedorka-Cray et al., 1998; Dargatz et al., 2000). In concentrated animal feeding operations (CAFO), cattle 
(Bos taurus) typically acquire $S$. enterica from other infected livestock which spread the pathogen throughout the herd via contaminated cattle feces (Wray and Davies, 2000), cattle feed (Maciorowski et al., 2006), and water (Kirk et al., 2002a). There is evidence that the ecological interactions between synanthropic birds and cattle also contribute to increased cattle fecal shedding and environmental contamination of CAFO with S. enterica, Escherichia coli 0157:H7 and Mycobacterium avium spp. paratuberculosis (Daniels et al., 2003; Carlson et al., 2011a; Kauffman and LeJeune, 2011; Shwiff et al., 2012). European starlings (Sturnus vulgaris) stand out as a potential source for $E$. coli 0157:H7 and S. enterica in CAFO (Carlson et al., 2011b; Cernicchiaro et al., 2012). In one instance, captured starlings shared genetically indistinguishable $E$. coli 0157 subtypes with cattle in two isolated dairies visited by the foraging flock (Williams et al., 2011). Based upon the published literature and our behavioral observations of starling-cattle interactions we hypothesize that crossspecies transmission of $S$. enterica occurs between starlings and cattle in CAFO. We predict that indistinguishable PFGE profiles would be found in starling and cattle samples involved in the cross-species transmission of S. enterica; starling feces (GI samples), cattle feces, external starling, cattle feed and cattle water trough samples.

The published data implicating starlings as a source for S. enterica contamination within CAFO has relied primarily upon direct plating and serotyping to demonstrate that $S$. enterica contamination is associated with starling-livestock interactions (Kirk et al., 2002b; Gaukler et al., 2009; Carlson et al., 2011a,b). These data have been useful at identifying associations between foraging flocks of starlings and $S$. enterica contamination of the CAFO environment, but these data cannot show that transmission is occurring between species or that shared feed sources are contributing to the infection process. Genetic identification is necessary to determine if $S$. enterica isolates obtained from starlings, livestock, and their shared feed and water sources are epidemiologically linked.

In this study we characterized patterns of XbaI-digested genomic DNA from $S$. enterica isolates collected from starlings and CAFO using pulsed-field gel electrophoresis (PFGE). PFGE profiling was completed for $182 \mathrm{~S}$. enterica isolates collected from a single CAFO between 2009 and 2012. All serotypes of $S$. enterica isolated from starling gastrointestinal tracts (GI), external starling wash, cattle feces, cattle feed and cattle water trough samples were included in the PFGE analysis. The objectives of this study were to: (1) determine if starling GI and cattle fecal samples share indistinguishable $S$. enterica profiles based upon XbaI-digested genomic DNA patterns; (2) determine if $S$. enterica isolates from starling GI and external wash samples are phylogenetically related to isolates originating from cattle feed and water sources; (3) determine if antimicrobial resistance (AMR) in $S$. enterica is associated with starling-cattle interactions.

\section{Methods}

All S. enterica samples used in this analysis originated from a single CAFO in Moore County, TX, USA. The CAFO produced feeder cattle and had a herd size of approximately 50,000 head. No other livestock were present and the CAFO had extremely high visitation rates of starlings ( $\geq 10,000$ starlings/day).

Detailed methodologies for collection of external starling washes, starling GI, cattle fecal, feed and water trough samples, and Colorado State University, Veterinary Diagnostic Laboratory (CSU-VDL) procedures for Salmonella culture, serotyping and the antimicrobial susceptibility testing have been described by Carlson et al. (in review). Briefly, 182 S. enterica isolates were used for PFGE analysis. Among these isolates 7 were collected in 2009, 35 were collected in 2010 and 140 were collected in 2012. Number of isolates included in PFGE analysis differed by serotype and source (Table 1). PFGE analysis was conducted following the PulseNet protocol developed by the Centers for Disease Control (CDC, 2013; Ribot et al., 2006). Standardized methods for molecular subtyping by PFGE are described below.

\subsection{PFGE plug preparation}

Frozen bacterial stock was cultured on Trypticase soy agar plates with 5\% sheep blood (TSA-SB; BD Diagnostics, Sparks, MD 21152). A single colony from each TSA-SB plate was removed and transferred to falcon 2054 tubes containing $2 \mathrm{~mL}$ of cell suspension buffer (CSB). Cell suspension concentration was adjusted to the desired optical density of $1.3-1.4 \mathrm{~nm}$ through incremental additions of CSB. Absorbance (optical density) measurements were made using a spectrophotometer.

\subsection{Casting plugs and digestion of genomic DNA}

A $200 \mu \mathrm{L}$ aliquot of cell suspension was transferred to a $1.5 \mathrm{~mL}$ microcentrifuge tube containing $10 \mu \mathrm{L}$ of proteinase K. Agarose mixture ( $200 \mu \mathrm{L} 1 \%$ SeaKem Gold; SKG) was added to each microcentrifuge tube, mixed gently and then dispensed into disposable PFGE plug molds.

Table 1

Salmonella enterica serotypes isolated by source. All samples were collected in a concentrated animal feeding operation in TX, USA between 2009 and 2012.

\begin{tabular}{|c|c|c|c|c|c|c|}
\hline Sample source & $\begin{array}{l}\text { Salmonella } \\
\text { Anatum }\end{array}$ & $\begin{array}{l}\text { Salmonella } \\
\text { Kentucky }\end{array}$ & $\begin{array}{l}\text { Salmonella } \\
\text { Montevideo }\end{array}$ & $\begin{array}{l}\text { Salmonella } \\
\text { Muenchen }\end{array}$ & $\begin{array}{l}\text { Salmonella } \\
\text { Meleagridis }\end{array}$ & Total \\
\hline Cattle fecal & 18 & 28 & 11 & 1 & 2 & 60 \\
\hline Water & 21 & 8 & 14 & 3 & 3 & 49 \\
\hline Feed & 6 & 12 & 4 & 3 & 4 & 29 \\
\hline Starling gastrointestinal & 15 & 3 & 6 & 2 & 1 & 27 \\
\hline Starling external wash & 5 & 3 & 2 & 5 & 2 & 17 \\
\hline Total & 65 & 54 & 37 & 14 & 12 & 182 \\
\hline
\end{tabular}


Plugs were removed from the molds after $15 \mathrm{~min}$ and placed into $50 \mathrm{~mL}$ conical tubes containing $5 \mathrm{~mL}$ of cell lysis buffer (CLB). Following an incubation period, plugs were washed with sterile water and again with sterile TrisEDTA (TE) buffer (10 mM Tris, 1 mM EDTA [pH 8.0]). Plugs were digested with $\mathrm{XbaI}$ restriction buffer immediately after preparation. Tris-Borate EDTA (TBE; $200 \mu \mathrm{L}$ of $0.5 \times$ ) was added to the microcentrifuge tubes and incubated at room temperature for $5 \mathrm{~min}$. Plug slices were removed and placed on the bottom of comb teeth and positioned in the gel frame. Salmonella ser. Braenderup H9812 standards were placed on lanes 1,7 , and 14 . Test samples were placed on lanes 2 through 6 and lanes 8 through 13. SKG agarose was then carefully poured into the gel frame and allowed to cool before the comb was removed.

\subsection{Separation of restriction fragments and visualization of gel bands}

The restriction fragments were separated in $2 \mathrm{~L}$ of $0.5 \times$ TBE buffer at $14^{\circ} \mathrm{C}$ using a CHEF Mapper electrophoresis unit (Bio-Rad, Hercules, CA 94547). CHEF Mapper was set to the following specifications: Auto Algorithm, $30 \mathrm{~kb}$ low MW, $700 \mathrm{~kb}$ high MW, runtime $18 \mathrm{~h}$, pulse time of 2.16$63.8 \mathrm{~s}$. Gels were stained with GelRed and DNA bands visualized with UV transillumination (Bio-Rad).

\subsection{Analysis of PFGE results}

PFGE profiles were analyzed using BioNumerics software (Applied-Maths, Kortrijk, Belgium). Banding patterns were compared using Dice coefficients with a $1.5 \%$ band position tolerance. Dendrograms with estimates of percent similarity were constructed for 182 isolates associated with five different S. enterica serotypes (Anatum, Kentucky, Meleagridis, Montivideo, Muenchen) using an unweighted pair group method and arithmetic average (UPGMA) clustering algorithm. Susceptible, intermediate and resistant (SIR) antimicrobial resistant patterns were included in the PGFE analysis for all $S$. enterica isolates collected in 2012.

Classification of $S$. enterica profiles were based upon the categories of genetic relatedness reported by Tenover et al. (1995). Based on this classification scheme isolates are assumed to be indistinguishable if their restriction patterns have the same number of bands and the corresponding bands are the same apparent size. All indistinguishable dendrogram banding patterns are referred to as clades. Clades of $S$. enterica isolates are grouped within their respective serogroups and identified by number.

\section{Results}

\subsection{S. enterica serotype Anatum}

A total of 65 S. Anatum isolates were analyzed (Fig. 1). Among the 65 isolates 4 were recovered in 2009, 17 were recovered in 2010, and 44 were recovered in 2012. A total of 6 clades were identified. Clade 5 accounted for $78.5 \%$ $(51 / 65)$ of all $S$. Anatum isolates. This clade contained isolates with indistinguishable PFGE profiles originating from cattle feces (15/51), cattle water troughs (17/51), cattle feed (4/51), external starling wash $(5 / 51)$, and starling GI samples (10/51). Isolates from this clade were recovered in 2009, 2010 and 2012. Two cattle fecal samples (4\%) were resistant to different antibiotics. All other tested isolates within clade 5 were susceptible to antibiotics, but $53 \%(27 / 51)$ had intermediate levels of susceptibility to streptomycin.

Clade 4 also contained isolates with indistinguishable PFGE profiles shared by both starlings and cattle. Within clade 4 isolates were recovered from starling GI (4/6), cattle feces (1/6) and cattle feed samples (1/6). Half the isolates (3/6) were resistant to one antibiotic. Two isolates were resistant to sulfisoxazole and the remaining isolate was resistant to streptomycin. The other isolates were susceptible to all antibiotics.

\subsection{S. enterica serotype Kentucky}

A total of $54 \mathrm{~S}$. Kentucky isolates were analyzed (Fig. 2). All isolates were recovered in 2012. A total of five clades were identified. Clade 4 accounted for $66 \%$ (36/54) of all $S$. Kentucky isolates. This clade contained isolates with indistinguishable PFGE profiles originating from cattle feces $(15 / 36)$, cattle water troughs $(7 / 36)$, cattle feed (11/ $36)$, external starling wash (2/36) and starling GI samples $(1 / 36)$. Within clade $5,61 \%(22 / 36)$ of isolates were resistant to sulfisoxazole, one isolate $(3 \%)$ showed resistance to streptomycin and 36\% (13/36) of isolates were susceptible to all antibiotics.

Clade 3 also contained isolates with indistinguishable PFGE profiles that were shared by both starlings and cattle. Within clade 3 isolates were recovered from cattle feces ( $5 /$ $8)$, cattle water troughs $(1 / 8)$, external starling wash $(1 / 8)$ and starling GI samples (1/8). Within clade 3,63\% (5/8) of isolates showed resistance to sulfisoxazole and tetracycline, $13 \%(1 / 8)$ showed resistance to tetracycline, $13 \%$ (1/ 8 ) showed resistance to sulfisoxazole and $13 \%(1 / 8)$ were susceptible to all antibiotics.

\subsection{S. enterica serotype Montevideo}

A total of $37 \mathrm{~S}$. Montevideo isolates were analyzed (Fig. 3). Among the 37 isolates one was recovered in 2009, 13 were recovered in 2010 and 23 were recovered in 2012. A total of six clades were identified. Clade 1 accounted for $67.6 \%(25 / 37)$ of all S. Montevideo isolates. This clade contains isolates with indistinguishable PFGE profiles originating from cattle feces $(11 / 25)$, cattle feed $(2 / 25)$, cattle water (5/25), external starling wash $(1 / 25)$ and starling GI samples (6/25). Isolates from this clade were recovered in 2010 and 2012. Only one isolate (4\%) showed resistance to antibiotics and it was resistant to sulfisoxazole and tetracycline.

\subsection{S. enterica serotype Muenchen}

A total of $14 \mathrm{~S}$. Muenchen isolates were analyzed (Fig. 4). All 14 isolates were recovered in 2012. A total of four clades were identified. Clade 1 accounted for $57 \%$ ( 8 / 

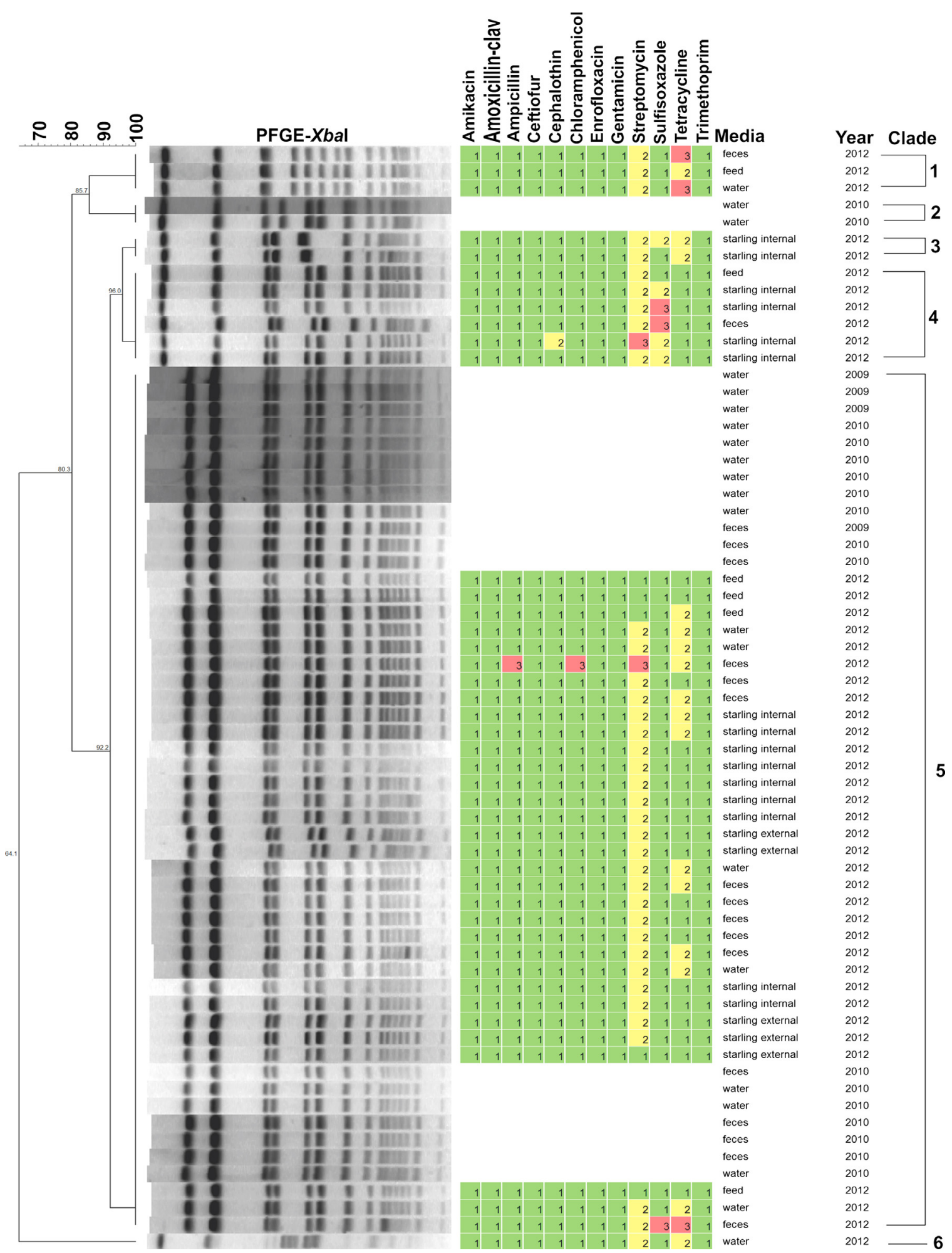

Fig. 1. Dendrogram of pulsed-field gel electrophoresis (PFGE) gel band patterns for $S$. Anatum isolates collected from cattle feces, cattle feed, cattle water troughs, external European starling wash and European starling gastrointestinal samples $(n=65)$. Dendrograms include antimicrobial resistant profiles determined by clinical and laboratory standard breakpoints; susceptible (1), intermediate (2) and resistant (3). Clades of indistinguishable isolates are identified within brackets. 


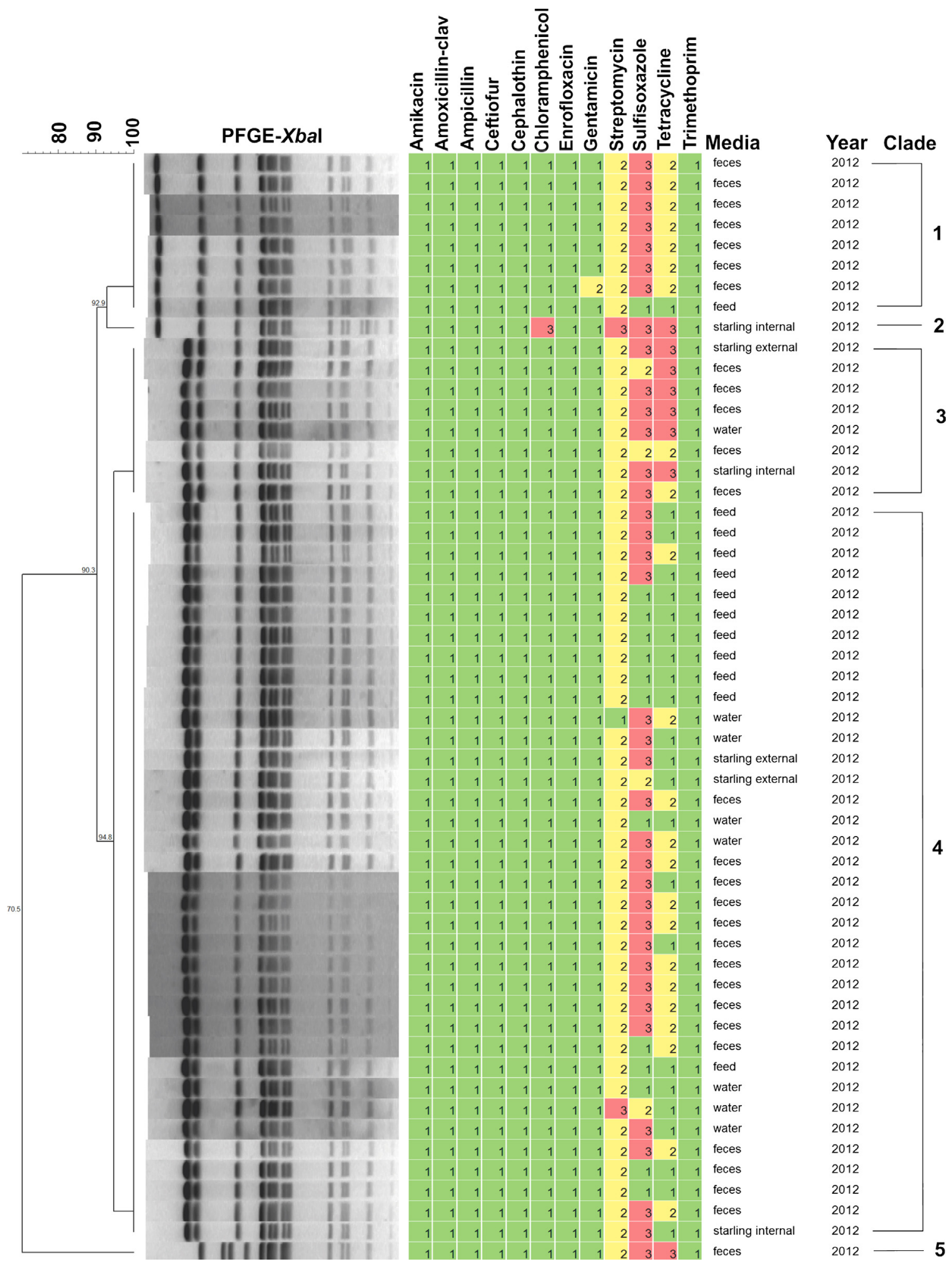

Fig. 2. Dendrogram of pulsed-field gel electrophoresis (PFGE) gel band patterns for $S$. Kentucky isolates collected from cattle feces, cattle feed, cattle water troughs, external European starling wash and European starling gastrointestinal samples $(n=54)$. Dendrograms include antimicrobial resistant profiles determined by clinical and laboratory standard breakpoints; susceptible (1), intermediate (2) and resistant (3). Clades of indistinguishable isolates are identified within brackets. 

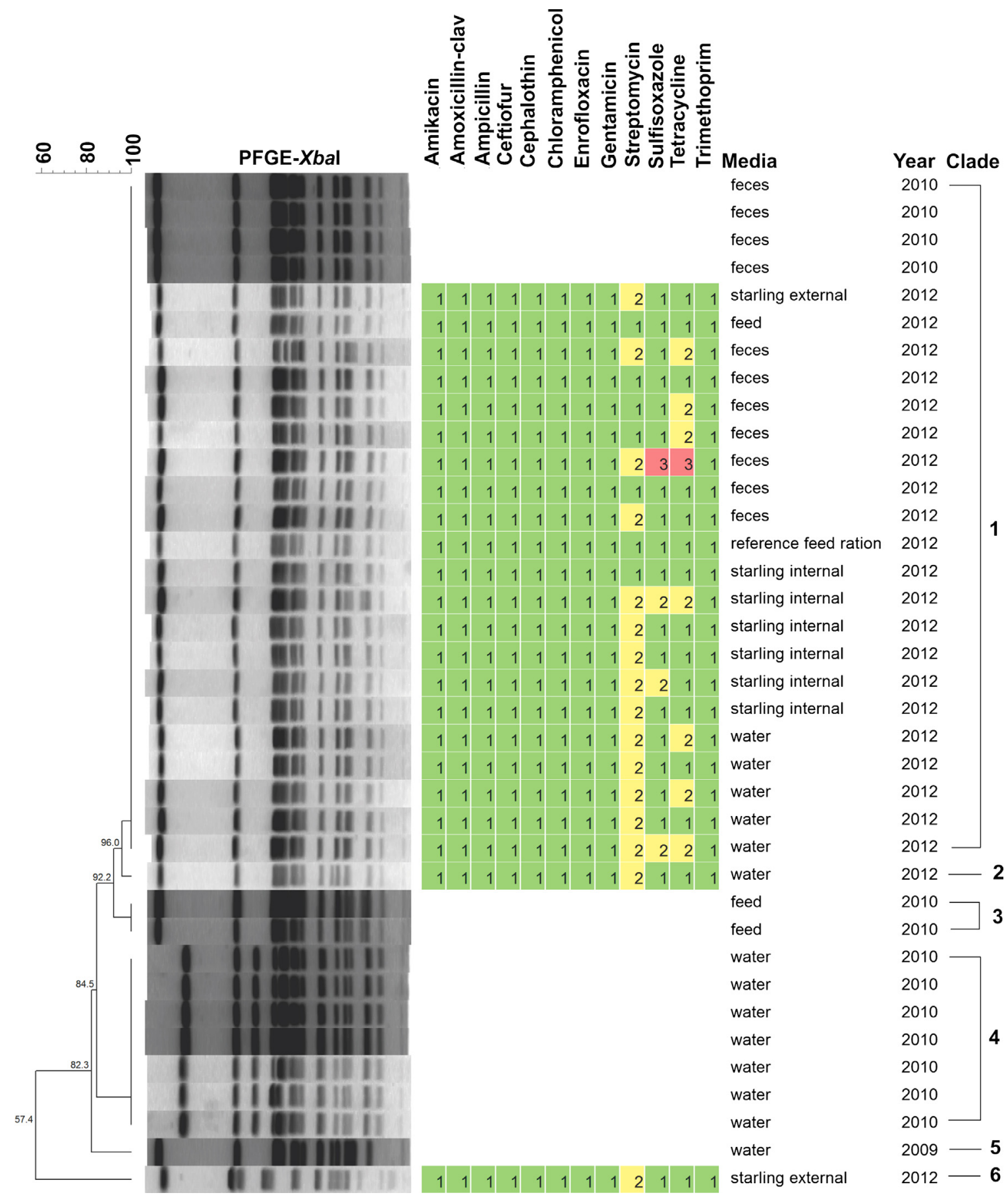

Fig. 3. Dendrogram of pulsed-field gel electrophoresis (PFGE) gel band patterns for $S$. Montivideo isolates collected from cattle feces, cattle feed, cattle water troughs, external European starling wash and European starling gastrointestinal samples $(n=37)$. Dendrograms include antimicrobial resistant profiles determined by clinical and laboratory standard breakpoints; susceptible (1), intermediate (2) and resistant (3). Clades of indistinguishable isolates are identified within brackets.

14) all S. Muenchen isolates. This clade contains isolates with indistinguishable PFGE profiles originating from cattle feed $(2 / 8)$, cattle water $(3 / 8)$, external starling wash $(2 / 8)$ and starling GI samples (1/8). No isolates originating from cattle feces were found in this clade. Within clade 1 ,
$25 \%(2 / 8)$ of isolates showed resistance to sulfisoxazole and one isolate (13\%) showed resistance to streptomycin.

Clade 4 also contained isolates shared by starlings and cattle feed. Within clade 4 isolates with indistinguishable PFGE profiles were recovered from cattle feed (1/4), 

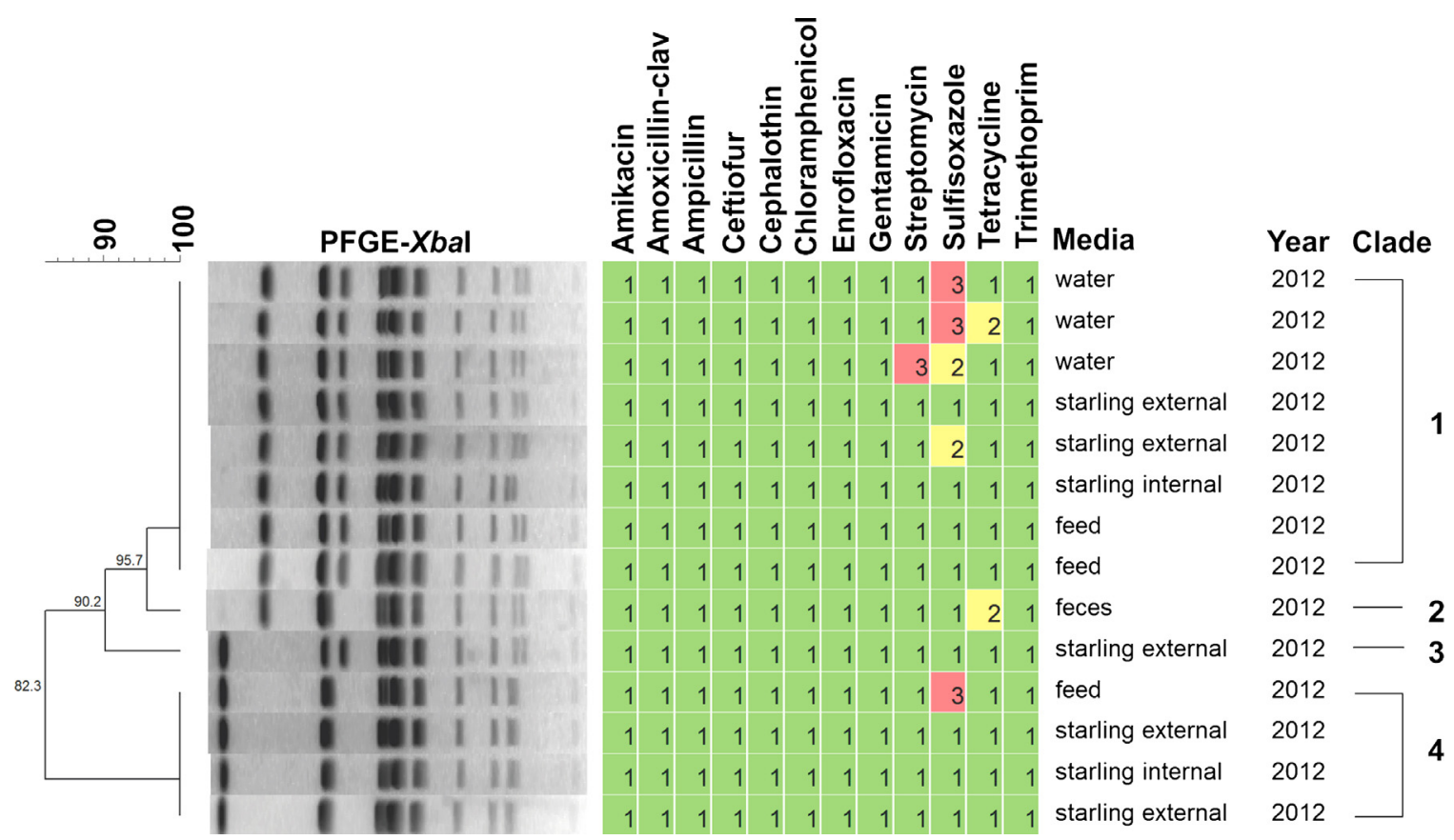

Fig. 4. Dendrogram of pulsed-field gel electrophoresis (PFGE) gel band patterns for $S$. Muenchen isolates collected from cattle feces, cattle feed, cattle water troughs, external European starling wash and European starling gastrointestinal samples $(n=14)$. Dendrograms include antimicrobial resistant profiles determined by clinical and laboratory standard breakpoints; susceptible (1), intermediate (2) and resistant (3). Clades of indistinguishable isolates are identified within brackets.

external starling wash (2/4), and starling GI samples (1/4). No isolates originating from cattle feces were found in this clade. One isolate (25\%) recovered from cattle feed showed resistance to sulfisoxazole.

\subsection{S. enterica serotype Meleagridis}

A total of $12 \mathrm{~S}$. Meleagridis isolates were analyzed (Fig. 5). Among the 12 isolates, 2 were collected in 2009, 5
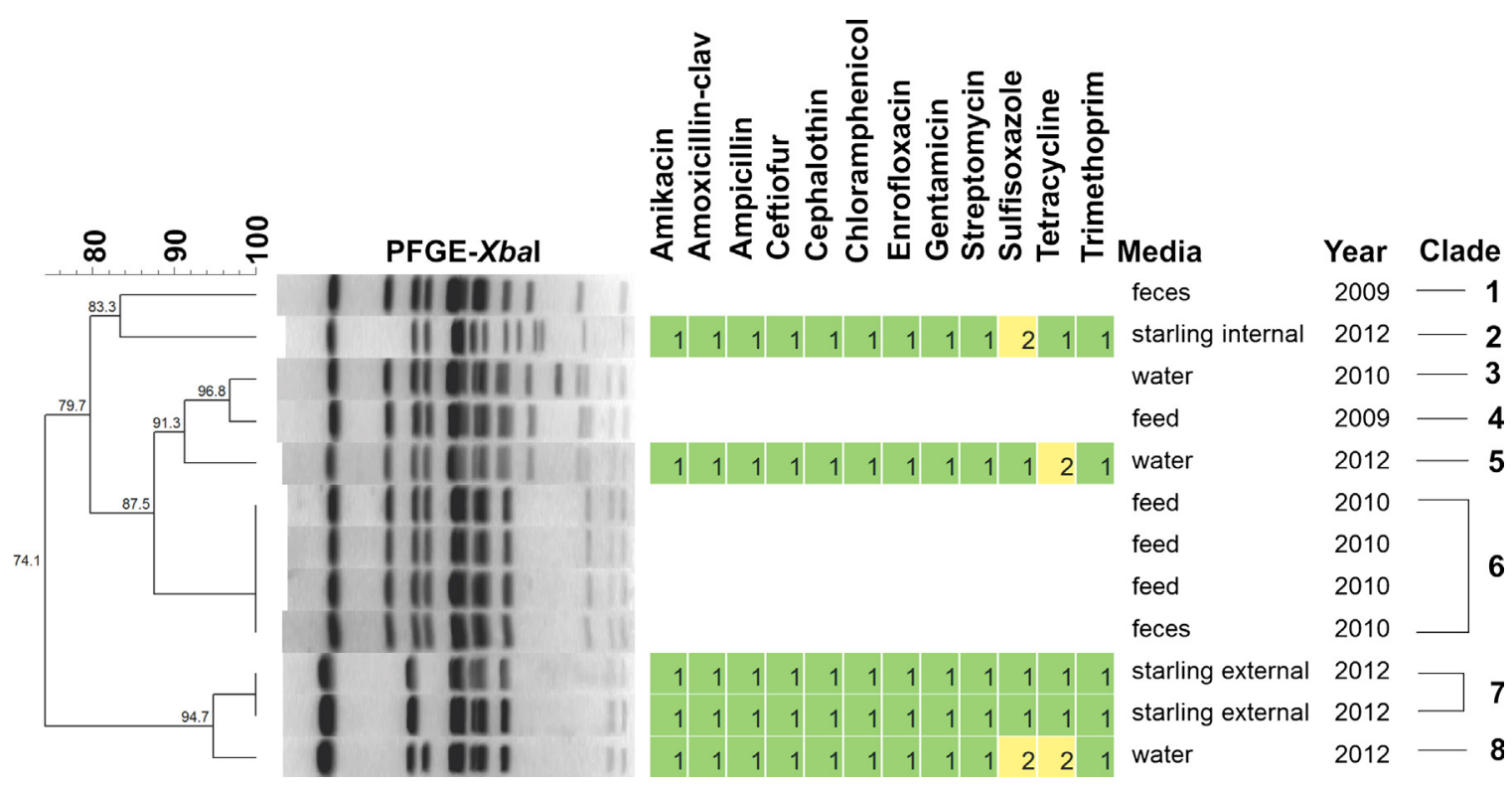

Fig. 5. Dendrogram of pulsed-field gel electrophoresis (PFGE) gel band patterns for $S$. Melagardis isolates collected from cattle feces, cattle feed, cattle water troughs, external European starling wash and European starling gastrointestinal samples $(n=12)$. Dendrograms include antimicrobial resistant profiles determined by clinical and laboratory standard breakpoints; susceptible (1), intermediate (2) and resistant (3). Clades of indistinguishable isolates are identified within brackets. 
were collected in 2010, and 5 were collected in 2012 . Starlings and cattle did not share indistinguishable PFGE profiles, nor were there indistinguishable PFGE profiles found between collection years. All S. Meleagridis isolates were susceptible to antibiotics.

\section{Discussion}

This manuscript contains important and novel data implicating starlings in the transmission ecology of $S$. enterica within the human food supply. Yet we would be remiss if we did not explicitly state that our samples were collected from a single CAFO. Readers should remember that it is conceivable other CAFO using different feed formulations, management practices, or raising other livestock may not show the same relationship between starlings and cattle that we document in this study.

Based upon the PFGE analysis of Xbal-digested genomic DNA, clades of $S$. Anatum, $S$. Kentucky, and $S$. Montivideo contained indistinguishable isolates recovered from starling GI tracts and cattle fecal samples. These data provides molecular evidence to support the hypothesis that interspecies transmission of $S$. enterica occurs when starlings interact with cattle in CAFO.

The data presented in this manuscript also provides molecular evidence to support the hypothesis that starlings contaminate cattle feed and water supplies with $S$. enterica as a consequence cattle feed consumption. Clades of $S$. Anatum, S. Kentucky, S. Montevideo and $S$. Muenchen contained isolates recovered from starling GI, feed and water samples. Clades from these same serotypes also contained isolates recovered from external starling wash, cattle feed and water supplies. Two clades of $S$. Muenchen contained isolates recovered from starling GI, starling external wash, cattle feed and water supplies but not from cattle feces. Thus, these data provides molecular evidence to support the hypothesis that starlings can act as fomites by mechanically moving $S$. enterica to cattle feed and water supplies (Carlson et al., in review).

The PFGE analysis revealed that $S$. enterica isolates are capable of persisting within a feedlot for multiple years. Indistinguishable isolates of $S$. Anatum were recovered in 2009, 2010 and 2012 and indistinguishable isolates of $S$. Montivideo were recovered in 2010 and 2012. Both of these clades contained $S$. enterica isolates recovered from starling GI tracts. Other publications have documented the persistence of $S$. enterica in agricultural environments for 5-6 years (Sandvang et al., 2000; Uesugl et al., 2007). To the best of our knowledge, our data is the first to implicate wild bird species as a contributor to long term environmental persistence of $S$. enterica in CAFO.

PFGE has good discriminatory power and has proven highly reliable (Heir et al., 2002) yet it is conceivable that the isolates we identify as indistinguishable actually differ slightly in terms of their chromosomal DNA patterns. PFGE can have difficulty discriminating between certain highly related strains of $S$. enterica; especially between $S$. Typhimurium DT104 isolates (Ribot et al., 2002.). This analysis would have benefited if our PFGE results were validated with a second restriction enzyme or PCR analysis. For example, multiple-locus variable-number tandem-repeats analysis (MLVA), could be used to validate subsets of isolates classified as indistinguishable based upon Xbal-digested genomic DNA patterns.

Serotypes of $S$. enterica commonly associated with infection in humans and animals have been identified in asymptomatic wild birds suggesting they may be persistent shedders of S. enterica (Sambyal and Sharma, 1972). Multiple publications have documented persistent $S$. enterica shedding by experimentally inoculated chickens for periods of at least 18-24 weeks (Gast and Holt, 1998; Immerseel et al., 2004). Based upon these previous reports and data collected in this study, starlings may persistently shed $S$. enterica after initial infection, serving as disseminators of the bacteria among CAFO and other habitats in which they occur. Experimental infections of starlings with $S$. enterica should be conducted to elucidate shedding patterns. Such data will be useful in developing risk assessments for persistence of $S$. enterica strains in CAFO.

This study documented a specific dominant clade in each of the $S$. Anatum, Kentucky and Montevideo strains. Isolates within each of these dominant clades were indistinguishable based upon PFGE analysis of XbaIdigested genomic DNA. Yet, variation in the phenotypic expression of antimicrobial resistance existed within each of these clades, suggesting that genes responsible for antimicrobial resistance were acquired through conjugated plasmids.

Horizontal transmission of AMR genes in food animals and wildlife may create serious public health risks (Smith et al., 2014; Van de Bogaard and Stobberingh, 2000). The unique ecology of starlings suggests these birds have the capacity to transport pathogenic bacteria and AMR genes from CAFO to urban and suburban environments. Starlings are known to use livestock facilities for food resources in winter when other natural food, such as insects and plant seeds, are limited (Dolbeer et al., 1978; Depenbusch et al., 2011). During the summer, starling use of CAFO is minimal because insects and other plant foods are plentiful and starlings have dispersed to rear young (Linz et al., 2007) in urban and suburban landscapes (Blair, 1996; Melles et al., 2003). Additionally, large winter roosts of starlings will occasionally occur in urban or suburban environments (Homan et al., 2006). It is conceivable that starlings are transporting $S$. enterica and AMR genes into human dominated landscapes and their unique ecological interactions with livestock and humans may create public health risks. Unfortunately there is not any data to assess if starling use of CAFO is associated with the vectoring or movement of pathogenic bacteria or AMR genes to environments that create to public health risks.

We recommend that future research examines the temporal and spatial scope of mechanical movement and GI vectoring of $S$. enterica by starlings. In particular research needs to examine if starlings can mechanically move $S$. enterica between otherwise isolated animal agricultural facilities and assess the public health risk associated with starling roosts and breeding within urban and suburban landscapes. 
This study was conducted using our banked $S$. enterica isolates collected between 2009 and 2012. The samples collected in 2009 and 2010 were originally used to document an association between starlings and contamination of cattle feed and water supplies (Carlson et al., 2011a,b). Unfortunately neither of these studies were able to show an association between starlings and cattle fecal shedding rates of $S$. enterica even when number of starlings on feedlots were reduced by $66 \%$. The PFGE data demonstrates that transmission between species is occurring and that shared feed sources likely contribute to the $S$. eneterica infection process in CAFO. Yet, the totality of this work suggests that starling introduced $S$. enterica does not drive the $S$. eneterica infection process in CAFO but instead is a secondary source of contamination, one that may be important for the movement and environmental persistence of $S$. enterica.

\section{Conflict of interests}

We have no conflict of interests to report.

\section{Acknowledgements}

This project was funded through the USDA/APHIS/ National Wildlife Research Center. Guidance and technical assistance was provided by Texas Wildlife Services and the National Wildlife Disease Program.

\section{References}

Blair, R.B., 1996. Land use and avian species diversity along an urban gradient. Ecol. Appl. 6, 506-519.

Carlson, J.C., Franklin, A.B., Hyatt, D.R., Pettit, S.E., Linz, G.M., 2011a. The role of starlings in the spread of Salmonella within concentrated animal feeding operations. J. Appl. Ecol. 2, 479-486.

Carlson, J.C., Engeman, R.M., Hyatt, D.R., Gilliland, R.L., DeLiberto, T.J., Clark, L., Bodenchuk, M.J., Linz, G.M., 2011b. Efficacy of European starling control to reduce Salmonella enterica contamination in a concentrated animal feeding operation in the Texas panhandle. BMC Vet. Res. 7, 9

Carlson J.C., Hyatt D.R., Ellis J.W., Pipkin D.R., Mangan A.M., Russell M., Bolte D.S., Engeman R.M., DeLiberto T.J., Linz G.M., Mechanisms of antimicrobial resistant Salmonella enterica transmission associated with starling-livestock interactions, Vet. Microbiol. (in review).

Cernicchiaro, N., Pearl, D.L., McEwan, S.A., Harpster, L., Homan, H.J., Linz, G.M., LeJeune, J.T., 2012. Association of wild bird density and farm management factors with the prevalence of E. coli 0157 in dairy herds in Ohio (2007-2009). Zoonoses Public Health 59, 320-329.

CDC PNL05, 2013. Standard operating procedure for PulseNet PFGE of Escherichia coli 0157:H7, Escherichia coli non-O157 (STEC), Salmonella serotypes, Shigella sonnei and Shigella flexneri, http://www.cdc. gov/pulsenet/PDF/ecoli-shigella-salmonella-pfge-protocol-508c. pdf.

Daniels, M.J., Hutchings, M.R., Greig, A., 2003. The risk of disease transmission to livestock posed by contamination of farm stored feed by wildlife excreta. Epidemiol. Infect. 130, 561-568.

Dargatz, D.A., Fedorka-Cray, P.J., Ladely, S.R., Ferris, K.E., 2000. Survey of Salmonella serotypes shed in feces of beef cows and their antimicrobial susceptibility patterns. J. Food Prot. 63, 1648-1653.

Depenbusch, B.E., Drouillard, J.S., Lee, C.D., 2011. Feed depredation by European starlings in a Kansas feedlot. Human-Wildl. Interact. 5, 5865.

Dolbeer, R.A., Wornecki, P.A., Strickley, J.R., White, S.B., 1978. Agricultural impact of a winter population of blackbirds and starlings. Wilson Bull. 90, 31-44.

Fedorka-Cray, P.J., Dargetz, D.A., Thomas, L.A., Gray, J.T., 1998. Survey of Salmonella serotypes in feedlot cattle. J. Food Prot. 61, 525-530.
Gast, R.K., Holt, P.S., 1998. Persistence of Salmonella enteritidis from one day of age until maturity in experimentally infected layer chickens, Poult. Sci. 77, 1759-1762.

Gaukler, S.M., Linz, G.M., Sherwood, J.S., Dyer, N.W., Bleier, W.J., Wannemuehler, Y.M., Nolan, L.K., Logue, C.M., 2009. Escherichia coli, Salmonella, and Mycobacterium avium subsp. paratuberculosis in wild European starlings at a Kansas feedlot. J. Avian Dis. 53, 544-551.

Heir, E., Lindstedt, B.A., Nygård, I., Vardund, T., Hasseltvedy, V., Kapperud, G., 2002. Molecular epidemiology of Salmonella Typhimurium isolates from human sporadic and outbreak cases. Epidemiol. Infect. 128, 373-382.

Homan, J.H., Linz, G.M., Unrein, G.W., Thiele, J.R., Hobbs, J.M., 2006. Movement of European starlings captured at a winter roost in Omaha, Nebraska. USDA-ARS/UNL Faculty (Paper 419)http://digitalcommons. unl.edu/usdaarsfacpub/419.

Immerseel, F.V., De Buck, J., Pasmans, F., Bohex, L., Boyen, F., Haesebrouck, F., Ducatelle, R., 2004. Intermittent long-term shedding and induction of carrier birds after infection of chickens early posthatch with a low or high dose of Salmonella enteritidis. Poult. Sci. 83, 19111916.

Kauffman, M.D., LeJeune, J., 2011. European starlings (Sturnus vulgaris) challenged with Escherichia coli 0157 can carry and transmit the human pathogen to cattle. Appl. Microbiol. 53, 569-601.

Kirk, J.H., Atwill, E., Holmberg, C., Arana, M., Collar, C., Ghirardelli, D., Higginbotham, G., Markagaard, G., Mullinax, D., Wubishet, A., 2002a. Prevalence of and risk factors for Salmonella in water offered to weaned dairy calves in California, USA. Prev. Vet. Med. 54, 169-178.

Kirk, J.H., Holmberg, C.A., Jeffrey, J.S., 2002b. Prevalence of Salmonella spp. in selected birds captured on California dairies. J. Am. Vet. Med. Assoc. 220, 359-362.

Linz, G.M., Homan, H.J., Gaukler, S.M., Penry, L.B., Bleier, W.J., 2007. European starlings: a review of an invasive species with far-reaching impacts. In: Witmer, G.W., Pitt, W.C., Fagerstone, K.A. (Eds.), Managing Vertebrate Invasive Species: Proceedings of an International Symposium. USDA/APHIS/WS, National Wildlife Research Center, Fort Collins, pp. 378-386.

Maciorowski, K.G., Herrera, P., Kundinger, M.M., Ricke, S.C., 2006. Animal feed production and contamination by foodborne Salmonella. J. Consum. Prot. Food Saf. 1, 197-209.

Majowicz, S.E., Musto, J., Scallan, E., Angulo, F.J., Kirk, M., O’Brien, S.J., Jones, T.F., Fazil, A., Hoekstra, R.M., 2010. The global burden of nontyphoidal Salmonella gastroenteritis. Food Saf. 50, 882-889.

Mead, P.S., Slutsker, L., Dietz, V., McCaig, L.F., Bresee, J.S., Shapiro, C., Griffin, P.M., Tauxe, R.V., 1999. Food-related illness and death in the United States. J. Emerg. Infect. Dis. 5, 607-625.

Melles, S., Glenn, S., Martin, K., 2003. Urban bird diversity and landscape complexity: species-environment association along a multiscale habitat gradient. Conserv. Ecol. 7, 5.

Pang, T., Bhutta, Z.A., Finlay, B.B., Altwegg, M., 1995. Typhoid fever and other salmonellosis: a continuing challenge. Trends Microbiol. 3, 253-255.

Ribot, E.M., Fair, M.A., Gautom, R., Cameron, D.N., Hunter, S.B., Swaminathan, B., Barrett, T.J., 2006. Standardization of pulsed-field gel electrophoresis protocols for the subtyping of Escherichia coli 0157:H7, Salmonella, and Shigella for PulseNet. Foodborne Pathog. Dis. 3, 59-67.

Ribot, E.M., Wierzba, R.K., Angulo, F.J., Barrett, T.J., 2002. Salmonella enterica serotype Typhimurium DT104 isolated from humans, United States, 1985, 1990, and 1995. Emerg. Infect. Dis. 8, 387-391.

Sambyal, D.S., Sharma, V.K., 1972. Screening of free-living animals and birds for listeria, Brucella, and Salmonella infections. Br. Vet. J. 128, 50-55.

Sandvang, D., Jensen, L.B., Baggesen, D.L., Baloda, S.B., 2000. Persistence of a Salmonella enterica serotype Typhimurium clone in Danish pig production units and farmhouse environment studied by pulsed field gel electrophoresis (PFGE). FEMS Microbiol. Lett. 187, 21-25.

Shwiff, S.A., Carlson, J.C., Glass, J.H., Suckow, J., Lowney, M.S., Moxcey, K.M., Larson, B., Linz, G.M., 2012. Producer survey of bird-livestock interactions in commercial dairies. J. Dairy Sci. 95, 6820-6829.

Smith, S., Wang, J., Fanning, S., McMahon, B.J., 2014. Antimicrobial resistant bacteria in wild mammals and birds: a coincidence or cause for concern. Ir. Vet. J. 67, 8

Tenover, F.C., Arbeit, R.D., Goering, R.V., Mickelsen, P.A., Murray, B.E., Persing, D.H., Swaminathan, B., 1995. Interpreting chromosomal DNA restriction patterns produced by pulsed-field gel electrophoresis: criteria for bacterial strain typing. J. Clin. Microbiol. 33, 2233-2239. 
Uesugl, A.R., Danyluk, M.D., Mandrell, R.E., Harris, L.J., 2007. Isolation of Salmonella enteritidis phage type 30 from a single almond orchard over a 5-year period. J. Food Prot. 70, 1784-1789.

Van de Bogaard, A.E., Stobberingh, E.E., 2000. Epidemiology of resistance to antibiotics links between animals and humans. Int. J. Antimicrob. Agents 14, 327-335.

Williams, M.L., Pearl, D.L., LeJeune, J.T., 2011. Multiple-locus variable nucleotide tandem repeat subtype analysis implicates European starlings as biological vectors for Escherichia coli 0157:H7 in Ohio, USA. Appl. Microbiol. 111, 982-988.
Wray, C., Davies, R.H., 2000. Salmonella infections in cattle. In: Wray, C., Wray, A. (Eds.), Salmonella in Domestic Animals. CABI Publishing, Cambridge, pp. 169-190.

Zhao, S., McDermott, P.F., Friedman, S., Abbott, J., Ayers, J., Glenn, A., HallRobinson, E., Hubert, S.K., Harbottle, H., Walker, R.D., Chiller, T.M., White, D.G., 2006. Antimicrobial resistance and genetic relatedness among Salmonella from retail foods of animal origin: NARMS retail meat surveillance. Foodborne Pathog. Dis. 3, 106-117. 